\title{
Chính sách "gác tranh chấp cùng khai thác" của Trung Quốc ở biển Đông và giải pháp cho Việt Nam
}

\author{
Nguyễn Bá Diến*, Nguyễn Hùng Cường \\ Khoa Luật, Đại học Quốc gia Hà Nội, 144 Xuân Thủy, Cầu Giấy, Hà Nội, Việt Nam \\ Nhận ngày 09 tháng 8 năm 2017 \\ Chỉnh sửa ngày 15 tháng 9 năm 2017; Chấp nhận đăng ngày 25 tháng 9 năm 2017
}

\begin{abstract}
Tóm tắt: Hợp tác cùng phát triển (khai thác chung) trên thực tế, là nhu cầu và cũng là giải pháp phù hợp có thể áp dụng cho việc giải quyết tranh chấp tại một số khu vực ở Biển Đông hiện nay. Tuy nhiên, Việt Nam phải hết sức thận trọng và nhận diện rõ tham vọng của Trung Quốc ẩn sau chính sách "gác tranh chấp cũng khai thác". Bài viết trình bày tổng quan về chính sách "gác tranh chấp cùng khai thác" này từ sự hình thành cho đến những nội dung cơ bản của chính sách. Từ đó, đề xuất các giải pháp cho Việt Nam để thực hiện hợp tác cùng phát triển (tiến hành khai thác chung) tại Biển Đông nhưng vẫn giữ vững chủ quyền của Việt Nam và các bên tranh chấp khác. Việt Nam sẽ chỉ tiến hành khai thác chung trên cơ sở Trung Quốc tôn trọng chủ quyền của Việt Nam đối với hai quần đảo Hoàng Sa và Trường $\mathrm{Sa}$ cũng như quyền chủ quyền và quyền tài phán của Việt Nam đối với vùng đặc đặc quyền kinh tế và thềm lục địa theo Công ước Luật Biển năm 1982.
\end{abstract}

Tù̀ khóa: Chính sách, gác tranh chấp, cùng khai thác, Trung Quốc, Biển Đông, giải pháp, Việt Nam.

Mô hình hợp tác cùng phát triển ${ }^{1}$ đã được thực hiện từ lâu trên thế giới, điển hình nhất là Hiệp ước Svalbard ngày 19/12/1920. Kể từ khi

\footnotetext{
*Tác giả liên hệ. ĐT.: 84-903426509.

Email: nbadien@yahoo.com

https://doi.org/10.25073/2588-1167/vnuls.4112

${ }^{1}$ Trong thực tiễn và pháp luật quốc tế hiện nay, các cụm từ "hợp tác cùng phát triển" và "hợp tác khai thác chung" đều được phiên dịch từ thuật ngữ gốc tiếng Anh là "joint development". Về bản chất có thể đồng nhất hai khái niệm này, nhưng về phạm vi ngữ nghĩa tiếng Việt cũng như căn cứ vào nội hàm và đặc điểm của chúng thì vẫn có những khác biệt nhất định, ví dụ như: phạm vi của hợp tác cùng phát triển rộng hơn hợp tác khai thác chung (thường tập trung vào hoạt động khai thác tài nguyên phục vụ lợi ích kinh tế), không chủ có vấn đề cùng khai thác tài nguyên mà còn bao hàm cả những hoạt động khác như nghiên cứu khoa học, trao đổi chuyên gia, trợ giúp kỹ thuật, tài chính, bảo vệ môi trường, hợp tác về an ninh,...
}

Hiệp ước này ra đời đến nay, trên thế giới đã có khoảng hơn 100 thỏa thuận hợp tác cùng phát triển được ký kết và thực hiện. Khoản 3 Điều 74 và Điều 83 Công ước Luật biển 1982 đã quy định rằng: "Trong khi chờ đợi ký kết thoả thuận nói ở khoản 1, các quốc gia hữu quan, trên tinh thần hiểu biết và hơp tác, làm hết sức mình để đi đến các dàn xếp tạm thời có tính chất thực tiễn và để không phuoong hại hay cản trở việc ký kết các thoả thuận dút khoát trong giai đoạn quá độ này. Các dàn xếp tạm thời không phuơng hại đến việc hoạch định cuối cùng”. Đây chính là cơ sở pháp lý quan trọng cho việc hình thành các thỏa thuận hợp tác cùng phát triển giữa các quốc gia. Hợp tác cùng phát triển (hợp tác khai thác chung) có ý nghĩa như là sụ làm "loãng" và "mềm" hoá nhũung xung đột, căng thẳng giữa các quốc gia hữu 
quan. Giải pháp này có thể tạm thời gác các tranh chấp, hạn chế tranh chấp có thể kéo dài ảnh hưởng đến quan hệ chính trị ngoại giao giữa các nước, hạn chế tình trạng căng thẳng có dẫn đến hoạt động chạy đua vũ trang hoặc dẫn đến các xung đột vũ trang. Trong xu thế hoà hoãn của quan hệ quốc tế sau chiến tranh lạnh, các nước trong khu vực Châu Á - Thái Bình Dương đã thúc đẩy hợp tác khai thác và phát triển chung, hợp tác quản lý biển chung. Các quá trình này đã làm cho môi trường an ninh trên biển dường như an bình hơn. Điểm lợi không thể phủ nhận của mô hình hợp tác cùng phát triển là đã góp phần xây dựng lòng tin, giảm tranh chấp và phát triển hợp tác kinh tế chính trị giữa các nước tham gia hợp tác. Mặt khác, hợp tác cùng phát triển là giải pháp tạm thời, không ảnh hưởng đến việc phân định cuối cùng, nên cũng có thể đáp ứng được nhu cầu khai thác tài nguyên phục vụ nhu cầu phát triển kinh tế [1].

Hợp tác cùng phát triển trên thực tế, là một giải pháp phù hợp có thể áp dụng cho việc dàn xếp tạm thời tranh chấp ở khu vực Biển Đông hiện nay, và hiện đang được các bên bàn bạc, cân nhắc. Hầu hết các nước ASEAN như Việt Nam, Philippines, Malaysia, Brunei đều có chung một mong muốn hòa bình giải quyết các tranh chấp biển, đảo, hướng tới sự ổn định trong khu vực, cố gắng kiềm chế trong ứng xử, không có các hành động làm phức tạp thêm tình hình. Chính nhận thức chung giữa các bên đã mở ra triển vọng và những điều kiện thuận lợi cho việc tiến hành các hoạt động hợp tác cùng phát triển trong khu vực. Tuy nhiên, chúng ta cần lưu ý rằng, xung quanh vấn đề hợp tác cùng phát triển tại Biển Đông, quan điểm của Trung Quốc (và cả Đài Loan) thể hiện có những điểm khác biệt so với quan điểm của các quốc gia khác. Trung Quốc là quốc gia đầu tiên chính thức đưa ra đề xuất khai thác chung tại khu vực quần đảo Trường $\mathrm{Sa}$ và cho đến nay dường như theo chủ trương "gác tranh chấp cùng khai thác" để giải quyết vấn đề Trường Sa. Điều đáng chú ý trong nội dung của quan điểm này là luận điểm khai thác chung trên cơ sở "chủ quyền thuộc về Trung Quốc (?!). Đây là điều mà Việt Nam và các bên tranh chấp khác không thể chấp nhận được. Pháp luật và thực tiễn hợp tác cùng phát triển trên thế giới, các quốc gia hữu quan tiến hành hợp tác trên cơ sở các bên có chủ quyền đối với khu vực tranh chấp và việc hợp tác không ảnh hưởng tới kết quả phân định cuối cùng. Ở đây, Trung Quốc khẳng định "chủ quyền" của Trung Quốc mà không đề cập tới chủ quyền của Việt Nam và các quốc gia khác, đồng thời không bao gồm quần đảo Hoàng Sa mà Trung Quốc đang chiếm đóng trái phép của Việt Nam. Do đó, quan điểm này của Trung Quốc là không có cơ sở pháp lý quốc tế và không được bất cứ quốc gia nào trong khu vực ủng hộ.

Trung Quốc chủ trương sủ dụng vấn đề hợp tác cùng phát triển ở Biển Đông với khẩu hiệu "gác lại tranh chấp cùng nhau khai thác". Tuy nhiên, chính sách này của Trung Quốc, ngay tù̀ khi mói được manh nha, đã bị công đồng quốc tế phản đối bởi tính chất bành trướng và tính phi pháp quốc tế của nó.

\section{Lược sử quan điểm của Trung Quốc về chủ trương "gác lại tranh chấp cùng nhau khai thác"}

Đối với quần đảo Hoàng Sa (của Việt Nam mà Trung Quốc đã dùng vũ lực xâm lược và chiếm đóng trái phép từ năm 1974), Trung Quốc luôn rêu rao là "thuộc chủ quyền không thể tranh nghị của Trung Quốc". Còn đối các vùng biển khác của Việt Nam, kể cả quần đảo Trường $\mathrm{Sa}$ (nơi Trung Quốc đã xâm chiếm và đã siêu đảo hóa phi pháp bảy thực thể), Trung Quốc dường như đang "ru ngủ" Việt Nam bằng sách lược "gác lại tranh chấp cùng nhau khai thác".

a. Sự hình thành quan điểm "gác lại tranh chấp cùng nhau khai thác"

Năm 1974, Nhật Bản và Hàn Quốc tiến hành khai thác chung dầu khí trong khu vực Đông Hải bất chấp sự phản đối của Trung Quốc cho rằng vùng biển này còn là vùng tranh chấp với sự tham gia của họ. Chính điều này đã 
khiến Trung Quốc xem xét tới việc khai thác chung trong vùng biển tranh chấp.

Chủ trương "Gác tranh chấp, cùng khai thác" được Trung Quốc chính thức đề nghị lần đầu tiên trong văn cảnh tranh chấp chủ quyền quần đảo Sen-ka-ku (tên Nhật)/Điếu Ngư Đài (tên Trung Quốc) giữa Nhật và Trung Quốc [2].

Trong chuyến thăm Nhật, ngày 25/10/1978, Thủ Tướng Trung Quốc Đặng Tiểu Bình nói với Thủ Tướng Nhật Takeo Fukuda rằng có thể để các thế hệ sau giải quyết tranh chấp chủ quyền đối với Sen-ka-ku/Điếu Ngư Đài; trong quan hệ ngoại giao, hai nước nên lấy quyền lợi chung làm ưu tiên [3]. Thực tế cho thấy Nhật và Trung Quốc đã đi theo phương hướng "gác tranh chấp" này. Điều đáng lưu ý là Nhật là nước đang kiểm soát Sen-ka-ku/Điếu Ngư Đài. Trong tranh chấp chủ quyền, nếu tranh chấp được gác lại thì có lợi cho nước đang kiểm soát lãnh thổ trong tình trạng tranh chấp. Vì vậy việc gác tranh chẩp có lợi cho Nhật hơn cho Trung Quốc. Trong bối cảnh vào cuối thập niên 1970, Trung Quốc cần mở rộng quan hệ quốc tế. Có lẽ vì nhu cầu đó Trung Quốc đã phải đề nghị gác tranh chấp Sen-ka-ku/Điếu Ngư Đài, một đề nghị có lợi cho Nhật hơn cho Trung Quốc trong phạm trù tranh chấp chủ quyền, để thuận tiện cho việc phát triển quan hệ với Nhật. Ngày 11/5/1979, Đặng Tiểu Bình nói với đại biểu quốc hội Nhật Zenko Suzuki rằng Trung Quốc và Nhật có thể cùng khai thác vùng biển lân cận đảo Sen-ka-ku/Điếu Ngư Đài mà không đề cập đến tranh chấp chủ quyền đối với đảo. Điều đáng lưu ý là Sen-ka-ku/Điếu Ngư Đài và vùng biển lân cận nằm dưới sự kiểm soát của Nhật, và vùng biển này gần Nhật và Đài Loan hơn Trung Quốc, cho nên Nhật có nhiều khả năng để đơn phương khai thác vùng biển này hơn Trung Quốc. Vì vậy, đề nghị của Trung Quốc để khai thác chung vùng biển này là một đề nghị có lợi cho Trung Quốc hơn là có tính xây dựng cho cả Trung Quốc và Nhật. Trên thực tế, cho tới nay, Nhật luôn luôn khước từ tất cả các đề nghị của Trung Quốc để khai thác vùng biển lân cận đảo này [2].

Khi Trung Quốc bắt đầu phát triển quan hệ ngoại giao với ASEAN trong hai thập niên
1970 và 1980, một phần là để mở rộng quan hệ ngoại giao, một phần là để đối trọng Việt Nam, Đặng Tiểu Bình đưa ra với ASEAN đề xuất về tranh chấp Trường Sa với luận điểm là:

- Quần đảo Trường Sa là một phần không tách rời được của Trung Quốc từ thời cổ xưa (?!)

- Tranh chấp chủ quyền phát sinh từ thập niên 1970.

- Vì quan hệ hữu nghị với những nước liên quan, Trung Quốc muốn tạm gác tranh chấp sang một bên và sau này tìm một giải pháp mà cả hai bên có thể chấp nhận được.

- Các bên nên tránh xung đột vũ trang và nên tìm cách khai thác chung ${ }^{2}$.

Tháng 2/1984, ông Đặng Tiểu Bình trong cuộc hội kiến với đoàn đại biểu Trung tâm nghiên cứu các vấn đề chiển lược và quốc tế trường đại học của Mỹ đã nói: "Có một số tranh chấp lãnh thổ trên thế giới có thể trước tiên không bàn tới vấn đề chủ quyền tiến hành cùng nhau khai thác" [4] thể hiện rõ quan điểm "gác lại tranh chấp cùng nhau khai thác". Năm 1984, Đặng Tiểu Bình một lần nữa trình bày quan điểm này: "Nhiều tranh chấp quốc tế nếu giải quyết không tốt sẽ dẫn tới xung đột", "Đối với tranh chấp quần đảo Trường $\mathrm{Sa}$, vừa có phương pháp tạm thời gác lại tranh chấp chủ quyền gay gắt, trên thực tế cũng còn có giải pháp cùng nhau khai thác". [2]

Tháng 6/1986, Đặng Tiểu Bình đề nghị với Phó Tổng Thống Phi-líp-pin Salvador Laurel rằng Trung Quốc và Phi-líp-pin nên gác tranh chấp Trường $\mathrm{Sa}$, "không nên để vấn đề này cản

\footnotetext{
${ }^{2}$ Bộ Ngoại giao Trung Quốc, đã dẫn: "When China entered into diplomatic relations with the Southeast Asian countries in the 1970s and 1980s, during talks with the leaders of these countries, Deng Xiaoping made the following reasonable proposal for resolving disputes over the Nansha Islands: The Nansha Islands have been an integral part of China's territory since the ancient times. But disputes have occurred over the islands since the 1970s. Considering the fact that China has good relations with the countries concerned, we would like to set aside this issue now and explore later a solution acceptable to both sides. We should avoid military conflict over this and should pursue an approach of joint development".
} 
trở tình hũu nghị của Trung Quốc với Phi-líppin và các nước khác"3. Tháng 4/1988, Đặng Tiểu Bình đề nghị với Tổng Thống Phi-líp-pin Corazon Aquino, "Xét quan hệ hũu nghi giũa hai nước chúng ta, chúng ta có thể tạm gác vấn đề này và tiếp cận theo huớng khai thác chung" ${ }^{4}$.

Ngay cả khi đề nghị gác tranh chấp, Đặng Tiểu Bình cũng "giải thích" rằng "Trung Quốc có chủ quyền đối với Trường $\mathrm{Sa"}$ (?!). Theo Bộ Ngoại giao Trung Quốc, Đặng Tiểu Bình nói thẳng rằng, "Các bản đồ thế giới luôn vẽ Truờng Sa thuộc Trung Quốc.", "Chúng tôi có nhiều bằng chứng. Các bản đồ thế giới của nhiều nước cũng chứng minh điều này" (?!). Đặng Tiểu Bình cũng nói với Tổng Thống Corazon Aquino rằng Trung Quốc có nhiều thẩm quyền nhất về vấn đề Trường $\mathrm{Sa}$ vì Trường Sa luôn luôn là một phần của lãnh thổ Trung Quốc ${ }^{5}($ ?!).

Nhu vậy, phương án "gác lại tranh chấp cùng nhau khai thác" của Trung Quốc được hình thành trên co sở quan điểm của Đặng Tiểu Bình tù̀ việc tham khảo các mô hình giải quyết

\footnotetext{
$\overline{3}$ Bộ Ngoại giao Trung Quốc, đã dẫn:

In June, 1986, Deng said to visiting Filipino Vice President Laurel: "We should leave aside the issue of the Nansha Islands for a while. We should not let this issue stand in the way of China's friendship with the Philippines and with other countries."

${ }^{4}$ Bộ Ngoại giao Trung Quốc, đã dẫn:

Deng Xiaoping once again brought up this idea when he met visiting Filipino President Aquino in April, 1988. Deng said: "In view of the friendly relations between our two countries, we can set aside this issue for the time being and take the approach of pursuing joint development."

${ }^{5}$ Bộ Ngoại giao Trung Quốc, đã dẫn:

In addition to proposing the approach of "setting aside difference and pursuing joint development", Deng Xiaoping also explained China's stand that it has sovereignty over the Nansha Islands. He explicitly pointed out that "the Nansha Islands have always been marked as part of China on the maps of the world. The Nansha Islands belong to China." "We have many evidences. The maps of the world in many countries also prove this." He also said to President Aquino that China is in a most authoritative position to address the issue of the Nansha Islands since they have always been a part of China's territory.
}

tranh chấp lãnh thổ trên thế giới, nhung một mặt ngang ngược khẳng định chủ quyền "không bàn cãi" của Trung Quốc đối với quần đảo Hoàng Sa (đang chiếm đóng trái phép của Việt nam) và quần đảo TrươngSa, mặt khác lại đề nghi gác tranh chấp cùng khai thác (?!).

Ngoài những phát biểu của Đặng Tiểu Bình, quan điểm này còn được những nhà lãnh đạo cấp cao Trung Quốc lặp lại nhiều lần trong các hội nghị quốc tế sau này.

Tháng 8/1990, tại Xin-ga-po, Thủ tướng Trung Quốc Lý Bằng đã chính thức đưa ra phương án "gác lại tranh chấp cùng nhau khai thác", khẳng định đây là chủ trương của Trung Quốc tiến tới giải quyết tranh chấp vùng biển Trường $\mathrm{Sa}$. Ông Lý Bằng còn ngang ngược tuyên bố: "Quần đảo Nam $\mathrm{Sa}$ là lãnh thổ của Trung Quốc, đây là sự thật không thể chối cãi. Trung Quốc hi vọng vào thời điểm thích hợp có thể lần lượt thoả thuận với các quốc gia hưu quan về các vấn đề còn tồn tại trên cơ sở hũu nghi" [5].

Ngày 27/3/1991, Bộ trưởng Bộ Ngoại giao Trung Quốc Tiền Kì Thâm trong cuộc họp báo tại Hội nghị lần 4 Đại hội đại biểu nhân dân toàn quốc khoá VII (Quốc hội khoá VII) cũng đã không giấu tham vọng bành trướng với tuyên bố: "Chủ quyền của quần đảo Nam Sa thuộc về Trung Quốc, điều này là rất rõ ràng. Sau chiến tranh thế giới thư II, chính phủ Trung Quốc đã tiếp nhận lại quần đảo Nam Sa, chủ truoong của chúng ta là dưới tình hình Trung Quốc có chủ quyền với quần đảo Nam $\mathrm{Sa}$, chúng ta đồng $\dot{y}$ thương luợng với các quốc gia hưu quan tới cùng khai thác. Nhung hiện nay vẫn chuva có kế hoạch cu thể nhu thế, cũng chura tới thời điểm bàn tổ chức các hội nghi nhu vậy" (?!).

Sau đó không lâu, ngày 7/6/1991, Chủ tịch nước CHND Trung Hoa trong chuyến viếng thăm In-đô-nê-xi-a đã chỉ rõ rằng: "Chúng tôi nhất quán chủ truoong dùng phưong thưc hoà bình giải quyết tranh chấp quốc tế và chủ truoong cùng nhau khai thác, điều này phù hơp với lơi ich các bên hưu quan" [6].

Ngày 21/7/1992, Bộ trưởng Ngoại giao Trung Quốc Tiền Kì Thâm tại Hội nghị Bộ 
trưởng các nước ASEAN lần thứ 25 khi đề cập tới vấn đề quần đảo Trường Sa đã nói: "Chúng tôi đưa ra chủ trương gác lai tranh chấp cùng nhau khai thác, muốn vào thời điểm thích hợp đàm phán với các nước hữu quan tìm kiếm giải pháp giải quyết, điều kiện chưa tới có thể tạm gác lại không ảnh hưởng tới quan hệ hai nước" [7].

Trong Báo cáo công tác của Chính phủ Trung Quốc năm 1993 về Hội nghị lần thứ nhất Đại hội đại biểu nhân dân toàn quốc khoá VIII ngày 15/8/1993 đã ghi rõ: "Trên cơ sở chủ quyền quần đảo Truờng $S a$ thuộc về nuoóc ta, chúng ta đura ra chủ truoong "gác lại tranh chấp, cùng nhau khai thác", nguyện nỗ lực vì sư ổn định lâu dài và hơp tác cùng có lợi trong khu vưc Nam Hải”.

Chủ trương "gác lại tranh chấp cùng nhau khai thác" của Trung Quốc cũng được nhấn mạnh trong nhiều cuộc hội đàm với lãnh đạo các nước sau này. Tháng $8 / 1997$, Thủ tướng Lý Bằng khi trả lời phỏng vấn tại cuộc họp báo nhân chuyến viếng thăm Ma-lay-xi-a đã nói: "Trong vấn đề Nam Sa, chính sách của chính phủ Trung Quốc là gác lại tranh chấp, cùng nhau khai thác, theo nhũng quy định của luật biển và luật pháp quốc tế có liên quan thông qua đàm phán hũu nghi, hoà bình giải quyết vấn đề này" [8].

Tháng 12/1997, Chủ tịch nước CHND Trung Hoa Giang Trạch Dân trong lễ ký tuyên bố hợp tác với lãnh đạo các nước ASEAN tại Xin-ga-po đã tuyên bố: "Không dùng vĩ lục và đe doa dùng vũ lưc. Các bên liên quan căn cứ theo luật pháp quốc tế được thù̀a nhận, bao gồm Công ước Luật Biển 1982 thông qua đàm phán và hiệp thương hũu nghị giải quyết tranh chấp Nam Hải” [9].

\section{b. Nội dung co bản của quan điểm "gác lại tranh chấp cùng nhau khai thác"}

Qua nghiên cứu bước đầu quan điểm của Trung Quốc về "gác lại tranh chấp, cùng nhau khai thác", có thể nhận rõ mấy điểm cơ bản sau đây:
Luận điểm thứ nhất: "chủ quyền thuộc về ta". Đối với quan điểm "gác lại tranh chấp cùng nhau khai thác, Đặng Tiểu Bình có đưa ra một tiền đề là "Trung Quốc có chủ quyền không phải bàn cãi đối với quần đảo Nam Sa" (?!). Bất luận vấn đề quần đảo Hoàng $\mathrm{Sa}$ hay vấn đề quần đảo Trường $\mathrm{Sa}$, tham vọng chủ quyền của Đặng Tiểu Bình là không thay đổi. Tháng 2 năm 1984, Đăng Tiểu Bình đã ngang nhiên tuyên bố yêu sách phi lý về Trường Sa: "Đó là lãnh thổ thuộc Trung Quốc... chúng tôi đã nhiều lần tuyên bố chủ quyền là của Trung Quốc, dù các nước có chiếm lĩnh hay không, chủ quyền vẫn thuộc về Trung Quốc" (?!). Đặng Tiểu Bình còn tuyên bố rằng: "chủ quyền không phải là vấn đề có thể thảo luận, đối với vấn đề chủ quyền chúng tôi tuyệt đối không nhượng bộ" (?!). Yêu sách tham vọng phi lý này còn được Đặng Tiểu Bình "tua" lại nhiều lần trong các cuộc hội kiến ngoại giao sau này.

Luận điểm thứ hai: "tôn trọng sự thật, gác lại tranh chấp". Trung Quốc cho rằng đảo Điếu Ngư, quần đảo Nam $\mathrm{Sa}$ (Trường $\mathrm{Sa}$ ) "đều là một bộ phận không thể chia cắt của lãnh thổ Trung Quốc" (?!). Nhưng, "do những thay đổi của thời đại, mặc dù quần đảo Nam $\mathrm{Sa}$ từ cổ đã là lãnh thổ của Trung Quốc nhưng hiện nay các đảo chủ yếu của Nam Sa đã bị 4 nước 5 bên khống chế, các vùng biển bị chia cắt bởi 6 nước 7 bên và đang có xu hướng mở rộng khiến cho vùng biển $\mathrm{Nam} \mathrm{Sa}$ từ vùng biển không có tranh chấp trở thành vùng biển tranh chấp có diện tích lớn nhất hiện nay trên thế giới" (?!). Và, phía Trung Quốc cho rằng, "trong điều kiện chưa thể giải quyết triệt để tranh chấp, có thể chưa bàn tới vấn đề chủ quyền mà gác lại tranh chấp, nhưng gác lại tranh chấp không có nghĩa là từ bỏ chủ quyền".

Luận điểm thứ ba: "hợp tác cùng có lợi, cùng nhau khai thác". Quần đảo Trường $\mathrm{Sa}$ (Nam Sa) nằm ở tuyến đường hàng hải quốc tế, liên kết giữa Thái Bình Dương và Ân Độ Dương, là hành lang biển Đông Á và Châu Đại Dương, không những có nguồn tài nguyên sinh vật phong phú mà còn giàu nguồn tài nguyên dầu khí. Hiện thăm dò được 8 bồn địa dầu khí, trữ lượng khoảng 30 tỉ tấn, được coi là "Vịnh 
Ba Tư thứ hai”. Chính phủ Trung Quốc nhấn mạnh, "quần đảo Trường $\mathrm{Sa}$ (Nam Sa) là lãnh thổ của Trung Quốc" (?!), nhưng để bảo vệ hoà bình ổn định khu vực, thúc đẩy hợp tác phát triển có thể trước tiên gác lại tranh chấp, tiến hành cùng nhau khai thác theo nguyên tắc cùng hưởng lợi ích, hợp tác cùng có lợi. Điều này có lợi cho mối quan hệ hữu nghị láng giềng giữa Trung Quốc và các quốc gia xung quanh, có lợi cho hoà bình và ổn định của khu vực Châu Á Thái Bình Dương, có lợi cho hoà bình và phát triển trên thế giới.

Luận điểm thứ tư: "hướng tới tương lai, hoà bình giải quyết". Mục đích của việc cùng nhau khai thác là thông qua hợp tác phát triển, tăng cường hiểu biết, tạo điều kiện cuối cùng giải quyết một cách hợp lí vấn đề chủ quyền bằng phương thức hoà bình. Đặng Tiểu Bình chỉ rõ: "Trong vấn đề quốc tế, tốt nhất là áp dụng phương thức hoà bình tăng cường giải quyêt hợp tình hợp lí". Ông còn nhấn mạnh: "Xem xét mối quan hệ giữa các quốc gia chủ yếu nên xuất phát từ lợi ích chiến lược của chính quốc gia đó". "Bây giờ chúng ta hãy nghĩ xa một chút, nhìn rộng một chút, không xuất phát từ lợi ích căn bản của Đảng và quốc gia ta, không thể có quyết định đúng, nhiều vấn đề không thể hạ quyết tâm làm được. "nhìn xa một chút" ở đây nghĩa là hướng tới tương lai, "trông rộng" nghĩa là nhìn vào lợi ích căn bản của quốc gia. Trong vấn đề quần đảo Trường $\mathrm{Sa}$, Đặng Tiểu Bình kiên trì quan điểm "gác lại tranh chấp cùng nhau khai thác". Ông tin tưởng chỉ cần kiên trì theo phương án này nhất định sẽ tìm được cách giải quyết trọn vẹn. Ông nói: "Tôi tin rằng chúng ta cuối cùng sẽ tìm ra phương án giải quyết tốt. Nếu thế hệ này không thể giải quyết, thế hệ sau sẽ thông minh hơn chúng ta, có thể tìm ra biện pháp giải quyêt." ${ }^{[2]}$

Tại hội thảo quốc tế với chủ đề "Biển Đông: tăng cường hợp tác vì an ninh và phát triển trong khu vực" ở Hà Nội ngày 26-27/11/2009 [10], GS. Ji Guoxing của Đại học Jiaotong, Thượng Hải, nguyên giám đốc bộ môn Châu Á - Thái Bình Dương của Viện Nghiên cứu Chiến lược Quốc tế Thượng Hải, nhắc lại chủ trương "gác tranh chấp, cùng khai thác" của Trung
Quốc. GS. Ji Guoxing đề xuất rằng, trước hết, các bên trong tranh chấp phải thoả thuận được một khuôn khổ chung cho việc khai thác trên toàn bộ Biển Đông. GS. Ji Guoxing cụ thể hoá bằng cách đề nghị Việt Nam và Trung Quốc bàn về khả năng cùng khai thác bãi Tư Chính, một khu vực nằm gần như hoàn toàn bên trong vùng đặc quyền kinh tế 200 hải lý từ lãnh thổ không bị tranh chấp của Việt Nam, không thuộc quần đảo Trường $\mathrm{Sa}$ vốn đang trong tình trạng tranh chấp chủ quyền [11]. Tại buổi họp báo ở Hà Nội ngày 6/1/2010 [12], Đại sứ Trung Quốc Tôn Quốc Tường cũng đề nghị chủ trương "gác tranh chấp, cùng khai thác". Đại sứ Tôn Quốc Tường nói, "Lãnh đạo cấp cao Trung Quốc đã nêu ra một sáng kiến mang tính xây dụng, đó là gác lại tranh chấp, cùng nhau khai thác", và đề nghị rằng Việt Nam và Trung Quốc nên tạm gác lại tranh chấp, đợi điều kiện chín muồi.

"Nếu điều kiện chín muồi, hai bên giải quyết được vấn đề, chắc chắn sẽ thúc đẩy phát triển quan hệ hai bên chúng ta. Nếu điều kiện chura chín muồi, làm cản trở cho quan hệ hai nước thì điều cần phái làm và nên làm là gác lai vấn đề. Trong quan hệ hai nước còn có nhiều công việc cần cố gắng, nỗ lưc, có nhiều hợp tác có thể tiến hành...Trong khi phát triển quan hệ song phuoong và chò đợi điều kiện chín muồi, hai bên có điều kiện giải quyết vấn đề này tốt hơn và sẽ đura ra phương án giải quyết hơp lý hon nũa."

Qua những nội dung cơ bản và cụ thể của quan điểm "gác lại tranh chấp cùng nhau khai thác", ta có thể thấy rằng những nội dung của quan điểm này có sự kế thừa những lý thuyết cơ bản về khai thác chung trên thế giới và có những nét riêng mang mầu sắc Trung Quốc. Điều đáng chú ý trong nội dung của quan điểm này chính là luận điểm đầu tiên chủ quyền thuộc về Trung Quốc. Trung Quốc khẳng định khai thác chung vùng biển Trường Sa trên cơ sở Trung Quốc có chủ quyền đối với quần đảo. Đây là điều Việt Nam cũng như các bên tranh chấp khác không thể chấp nhận. Thực tiễn khai thác chung trên thế giới, các quốc gia hữu quan tiến hành khai thác chung trên cơ sở các bên có chủ quyền đối với khu vực tranh chấp và việc 
khai thác chung không ảnh hưởng tới kết quả phân định cuối cùng. Ở đây Trung Quốc khẳng định chủ quyền của mình mà không đề cập tới chủ quyền của Việt Nam và các bên tranh chấp khác ở Biển Đông. Bên cạnh đó, chủ trương "gác tranh chấp, cùng khai thác" của Trung Quốc không bao gồm quần đảo Hoàng $\mathrm{Sa}$, nơi Trung Quốc đang chiếm đóng trái phép của Việt Nam. Thậm chí, Trung Quốc còn cho rằng "không tồn tại tranh chấp chủ quyền đối với quần đảo Hoàng Sa", vì "Trung Quốc có chủ quyền không thể chối cãi đối với Hoàng $\mathrm{Sa}$ (Tây Sa)" (?!) và "Trung Quốc và Việt Nam không có tranh chấp về vấn đề này" ${ }^{\prime \prime}($ ?!). .

Như vậy, Việt Nam cũng như các quốc gia hữu quan không thể chấp nhận quan điểm "gác lại tranh chấp cùng nhau khai thác" của phía Trung Quốc đưa ra với những yêu sách chủ quyền phi lý và ngang ngược nêu trên!

Xét về mặt hình thức, đề xuất "gác tranh chấp, cùng khai thác" (hợp tác cùng phát triển) của Trung Quốc là phù hợp với luật pháp và thực tiễn quốc tế, như là một giải pháp tạm thời đối với các tranh chấp phức tạp như tranh chấp ở một số khu vực ở Biển Đông. Tuy nhiên, vấn đề then chốt là ở chỗ Trung Quốc chỉ muốn "gác tranh chấp, cùng khai thác" trên khu vực thềm lục địa mà Việt Nam và các quốc gia ven biển khác được hưởng một cách hợp pháp theo quy định của luật pháp quốc tế. Như vậy, xét dưới góc độ luật pháp và thực tiễn quốc tế thì yêu sách của Trung Quốc là không có cơ sở

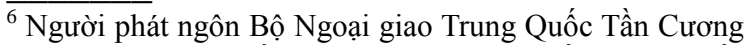
trả lời phóng viên về việc Việt Nam phản đối Trung Quốc tập trận tại Hoàng Sa. Foreign Ministry Spokesperson Qin Gang's Regular Press Conference on 27 November, 2007. Bộ Ngoại giao Trung Quốc, 28/11/2007.

http://big5.fmprc.gov.cn/gate/big5/tr.chinaembassy.org/eng/fyrth/t385091.htm

Q: It was reported that Vietnam protested against China's military exercise in Xisha Islands, regarding it as a "violation" of its "sovereignty". Do you have any comment?

A: It is known to all that China has undeniable sovereignty over the Xisha Islands and its adjacent islets. China and Vietnam have no dispute over this issue. The routine training of the Chinese navy is an ordinary activity within Chinese waters under China's sovereignty. Vietnam's protest is totally groundless.
}

pháp lý quốc tế và khó có thể được bất cứ quốc gia nào trong khu vực thừa nhận.

Hợp tác cùng phát triển (khai thác chung), trên thực tế, là giải pháp phù hợp có thể áp dụng cho việc giải quyết tranh chấp tại một số khu vực ở Biển Đông hiện nay và việc các quốc gia hữu quan ngồi vào bàn đàm phán bàn bạc những vấn đề cụ thể cho việc thực thi phương án này như là một trong những phương thức giải quyết xung đột khả thi cần phải được các bên tính đến, trong đó có Việt Nam. Tuy nhiên, để thực hiện giải pháp hợp tác cùng phát triển (tiến hành khai thác chung) tại Biển Đông, việc đầu tiên mà Việt Nam chắc chắn phải đề cập tới là vấn đề chủ quyền của Việt Nam với các bên tranh chấp khác. Việt Nam sẽ chỉ tiến hành khai thác chung trên cơ sở Trung Quốc tôn trọng chủ quyền của Việt Nam đối với hai quần đảo Hoàng $\mathrm{Sa}$ và Trường $\mathrm{Sa}$ cũng như quyền chủ quyền và quyền tài phán quốc gia của Việt Nam đối với vùng đặc đặc quyền kinh tế và thềm lục địa theo Công ước Luật Biển năm 1982.

\section{Một số đề xuất cho Việt Nam}

Qua nghiên cứu các thỏa thuận hợp tác cùng phát triển trên thế giới, có thể rút ra một số kinh nghiệm tham khảo phục vụ cho việc tiến hành đàm phán, ký kết và thực hiện các điều ước quốc tế về hợp tác cùng phát triển giữa Việt Nam và các nước ở Biển Đông như sau:

Thư nhất, việc đàm phán, ký kết và thực thi các thỏa thuận hợp tác cùng phát triển cần quán triệt nguyên tắc tôn trọng chủ quyền, quyền chủ quyền và quyền tài phán của Việt Nam đối với hai quần đảo Hoàng $\mathrm{Sa}$, Trường $\mathrm{Sa}$ và các vùng biển, đảo khác theo quy định của pháp luật quốc tế; nhất là trong phạm vi 200 hải lý vùng đặc quyền kinh tế và thềm lục địa của Việt Nam theo Công ước Luật Biển năm 1982 của Liên hợp quốc.

Không để nước ngoài thực hiện âm mưu: "biến vùng không có tranh chấp thành có tranh chấp" (ví dụ: khu vực Tư Chinh nằm hoàn toàn trong vùng đặc quyền kinh tế 200 hải lý của Việt Nam), hoặc "biến vùng đang có tranh chấp 
thành khu vực không có tranh chấp" (ví dụ quần đảo Hoàng Sa đang bị Trung Quốc xâm chiếm một cách phi pháp); cảnh giác với âm mưu của Trung Quốc thông qua hợp tác khai thác chung nhằm hiện thực hóa từng bước tham vọng và yêu sách "đường chín đoạn" phi lý của họ. Vì vậy, hợp tác ở khu vực nào, về lĩnh vực gì, mô hình pháp lý nào, với ai và vào thời điểm nào... cần có sự nghiên cứu, xem xét, tính toán hết sức kỹ lưỡng với những phương án hết sức chi tiết, khoa học và đồng bộ. Tuyệt đối không được phép chủ quan, khinh suất, tùy tiện, cảm tính. Nếu không, hậu quả sẽ khôn lường!

Việc khẳng định và bảo lưu nguyên tắc tôn trọng chủ quyền của Việt Nam đối với hai quần đảo Hoàng $S a$ và Trường $S a$ cũng như các vùng biển đảo khác dưới ánh sáng của pháp luật quốc tế. Các điều ước hợp tác cùng phát triển là một giải pháp tạm thời khi chưa có sự thống nhất phân định giữa Việt Nam và các quốc gia liên quan. Với tính chất như vậy, thỏa thuận hợp tác cùng phát triển sẽ "tạm gác" lại các tuyên bố và yêu sách chủ quyền để khai thác hiệu quả các nguồn tài nguyên biển cũng như hợp tác các lĩnh vực khác trên tinh thần "hợp tác và thiện chí có nguyên tắc", làm mềm hóa tranh chấp, hóa giải xung đột, tạo sự hiểu biết và tin cậy giữa các bên, chuẩn bị những điều kiện cơ bản cho việc giải quyết dứt điểm việc phân định cũng như các tranh chấp về biển đảo trong tương lai.

Thư hai, việc ký kết các điều ước về hợp tác cùng phát triển cần tuân thủ các nguyên tắc cơ bản của pháp luật quốc tế, Hiến chương Liên hợp quốc, đặc biệt là Công ước Luật biển năm 1982.

Thư $b a$, về nội dung hợp tác cùng phát triển (sẽ được thể hiện trong văn bản điều ước quốc tế giữa các bên hữu quan), cần được quy định chi tiết, toàn diện về tất cả các vấn đề có liên quan đến vùng hợp tác cùng phát triển như: xác định phạm vi hợp tác, tỷ lệ phân chia lợi nhuận, mô hình quản lý, các quy định về quyền và nghĩa vụ, việc xây dựng và sử dụng các công trình thiết bị, trao đổi thông tin, bảo vệ môi trường,... Có thể tham khảo kinh nghiệm các vấn đề này từ Hiệp định và Nghị định thư giữa
Senegal và Guinea Bissau; Hiệp định 1989 giữa Indonesia và Australia; Hiệp định phân định biển giữa Jamaica và Columbia 1993... Đồng thời, thỏa thuận phải hàm chứa những điều khoản nhằm đảm bảo rằng: tại khu vực hợp tác, các bên có quyền và lợi ích công bằng trong việc thăm dò, khai thác các lợi ích từ khu vực, xây dựng và quản lý các công trình phục vụ cho việc khai thác, nghiên cứu. Mỗi hoạt động đều đảm bảo sự tham gia của tất cả các bên, cùng gánh vác nghĩa vụ và chịu trách nhiệm về hoạt động của mình. Đối với các thỏa thuận về khai thác chung, cần đưa ra được những biện pháp để bảo tồn các loài cá và tài nguyên sinh vật khác.

$T h u ̛$ t $t u$, về quyền và nghĩa vụ của các bên, điều ước về hợp tác cùng phát triển nên quy định cụ thể, rõ ràng về các quyền và nghĩa vụ của mỗi trong vùng hợp tác. Đối với lĩnh vực nghề cá, ngoài các quy chuẩn về đánh bắt như sản lượng đánh bắt cá thì cần quy định thêm số lượng tàu thuyền đánh bắt cá của mỗi bên hàng năm.

Thư năm, đối với thẩm quyền tài phán của các bên, thỏa thuận về hợp tác cùng phát triển cần có các quy định chi tiết, cụ thể quyền và nghĩa vụ của các bên trong việc thực hiện thẩm quyền tài phán hành chính, hình sự, dân sự, khai thác tài nguyên... trên vùng hợp tác. Đặc biệt, nguyên tắc "cùng thực hiện thẩm quyền tài phán" cần được cân nhắc bởi trong bất kỳ trường hợp nào thì đây cũng là một nguyên tắc công bằng, đảm bảo sự lâu dài cho hợp tác của các bên. Ngoài ra, thỏa thuận còn cần quy định về thẩm quyền của các quốc gia đối với vấn đề an ninh và an toàn hàng hải nhằm tạo điều kiện cho các hoạt động hàng hải diễn ra an toàn, thuận lợi, vừa đảm bảo an toàn cho các hoạt động diễn ra tại các thương cảng lớn của các quốc gia hữu quan và đảm bảo chủ quyền quốc gia trên các vùng biển thuộc chủ quyền, quyền chủ quyền và quyền tài phán của mình. Bên cạnh đó, thỏa thuận nên có những quy định về vấn đề quyền, nghĩa vụ của quốc gia thứ ba trong vùng hợp tác.

Thư sáu, về việc xây dựng mô hình quản lý khu vực hợp tác cùng phát triển, thỏa thuận có 
thể xây dựng theo mô hình "đồng quản lý" được áp dụng trong Hiệp định giữa Senegal và Guinea Bissau và nhiều Hiệp định hợp tác chung nghề cá như Ủy ban liên hợp ngư nghiệp Trung - Nhật trong Hiệp định Ngư nghiệp giữa Trung Quốc và Nhật Bản ngày 11/11/1997, Ủy ban ngư nghiệp Nhật - Hàn trong Hiệp định ngư nghiệp Nhật Bản và Hàn Quốc ngày 28/11/1998, Ủy ban liên hợp nghề cá Việt Trung trong Hiệp định hợp tác nghề cá Việt Nam và Trung Quốc năm 2000... Mô hình này phải có sự phân cấp rõ ràng về chức năng, nhiệm vụ, quyền hạn của từng cơ quan và có các cơ quan chuyên môn phụ trách từng mảng vấn đề.

Thư bảy, về vấn đề tài chính, các điều khoản về tài chính phải được quy định rất cụ thể, bởi mục tiêu chủ yếu của các quốc gia khi hợp tác cùng phát triển là kinh tế. Các bên khi ký kết thỏa thuận hợp tác cùng phát triển cần dựa trên nguyên tắc công bằng để chia sẻ các quyền lợi và nghĩa vụ về tài chính. Các quốc gia thành viên sẽ được hưởng/gánh chịu phần dư/sự thâm hụt ngân sách theo tỷ lệ đã thỏa thuận.

Thư tám, về vấn đề luật áp dụng và giải quyết tranh chấp sẽ do hai bên thống nhất, tuy nhiên, cần triệt để tuân thủ các nguyên tắc, quy định của pháp luật quốc tế, có tính đến các điều kiện đặc thù của từng khu vực diễn ra hợp tác khai thác chung.

Thư chín, về thời hạn hợp tác cùng phát triển, điều ước về hợp tác cùng phát triển thường quy định văn bản này sẽ có hiệc lực kể từ thời điểm được cơ quan có thẩm quyền của mỗi bên chấp thuận và hết hiệu lực khi các bên đã đi đến thống nhất trong phân định. Các điều ước hợp tác cùng phát triển ở khu vực Biển Đông cũng nên quy định "mở” đối với các vấn đề xem xét lại, sửa đổi và bổ sung bằng các thủ tục thương lượng. Đây là một quy định khá đơn giản, tạo điều kiện thuận lợi cho việc xem xét lại hoặc sửa đổi, bổ sung cho hợp lý.

Thư mười, lý luận và thực tiễn đã chứng minh rằng, việc thiết lập và thực thi có hiệu quả các thỏa thuận hợp tác cùng phát triển trên biển giữa các quốc gia là kết quả của rất nhiều yếu tố tổng hợp và cần phải có sự nghiên cứu và đầu tư thỏa đáng từ phía Nhà nước, các tổ chức và cá nhân hữu quan. Các thỏa thuận hợp tác cùng phát triển đòi hỏi các điều kiện đảm bảo nhất định như:

i) Mối quan hệ giữa các quốc gia hữu quan, thiện chí của các bên về vấn đề hợp tác cùng phát triển, trong đó, ý chí chính trị của Nhà nước có vai trò và ý nghĩa quan trọng nhất, chi phối việc thiết lập hay hủy bỏ quan hệ hợp tác cùng phát triển.

ii) Điều kiện kinh tế - xã hội, cơ sở vật chất kỹ thuật, nguồn lực tài chính, nguồn nhân lực tham gia thực thi hoạt động hợp tác cùng phát triển. Nếu điều kiện của các quốc gia tham gia hợp tác cùng phát triển ngang bằng nhau hoặc không quá chênh lệch thì việc hợp tác sẽ thuận lợi hơn. Nếu tương quan các điều kiện chênh lệch rõ rệt thì khi ký kết các điều khoản hợp tác, các quốc gia cần bàn bạc, thống nhất và quy định thật chi tiết, rõ ràng quyền, nghĩa vụ, cách thức, tỷ lệ... trong những điều khoản này.

Thư mười một, học tập và vận dụng kinh nghiệm hợp tác cùng phát triển từ các thỏa thuận đã và đang có trên thế giới. Cho đến nay, trên thế giới đã có hàng trăm thỏa thuận hợp tác cùng phát triển được thiết lập trên các vùng biển thuộc các châu lục Á, Ầu, Phi, Mỹ, Úc, đặc biệt là tại các vùng biển có nhiều yêu sách chủ quyền chồng lấn giữa các quốc gia ven biển. Trong quá trình đàm phán, ký kết các điều ước hợp tác cùng phát triển (song phương hoặc đa phương), các quốc gia thường nghiên cứu, tham khảo các mô hình đã được áp dụng hoặc thiết lập trước đó, vận dụng phù hợp với hoàn cảnh, điều kiện thực tế tại vùng biển có nhu cầu và cơ sở tiến hành việc hợp tác. Các thỏa thuận đã được xây dựng trở thành hình mẫu tham khảo cho việc thiết lập các thỏa huận tiếp theo. Xuất phát từ thực tiễn đa dạng của các hoạt động hợp tác cùng phát triển, cần thiết phải tiếp tục tổ chức nghiên cứu, đánh giá một cách chi tiết, toàn diện các mặt ưu, nhược điểm của các mô hình hợp tác cùng phát triển dưới nhiều góc độ pháp lý, chính trị, ngoại giao, kinh tế,... nhằm đưa ra những luận cứ khoa học xác đáng 
cho việc hoàn thiện hệ thống lý luận về hoạt động hợp tác cùng phát triển ở các vùng biển cũng như định hướng và hỗ trợ thực thi các thỏa thuận về hợp tác cùng phát triển trên các vùng biển giữa các quốc gia, đặc biệt là ở khu vực Biển Đông.

Thú mười hai, để ký kết và thực thi hoạt động hợp tác cùng phát triển một cách hiệu quả, Việt Nam cần đặc biệt chú trọng các vấn đề sau:

Một là, đảm bảo các điều kiện kinh tế - xã hội, cơ sở vật chất kỹ thuật, nguồn lực tài chính... tham gia thực thi hoạt động hợp tác khai thác chung nhằm đạt được hiệu quả cao nhất. Thực tiễn cho thấy, nếu các điều kiện này của mỗi quốc gia tham gia khai thác chung là tương đồng hoặc không quá chênh lệch thì việc thực thi thỏa thuận khai thác chung sẽ thuận lợi, ít phát sinh những vấn đề khó khăn cần giải quyết. Đây cũng chính là lý do vì sao mỗi quốc gia khi tính đến việc thiết lập quan hệ hợp tác khai thác chung với quốc gia khác cần cân nhắc và chú trọng đến những điều kiện kinh tế, xã hội nhằm đảm bảo cho sự thành công của hoạt động khai thác chung.

Hai là, phát triển nguồn nhân lực: Vấn đề nhân lực luôn là một trong những vấn đề hàng đầu trong mọi hoạt động của đất nước. Để xây dựng và thực thi mô hình hợp tác cùng phát triển trên Biển Đông một cách hiệu quả, Việt Nam cần tăng cường, đẩy mạnh chất lượng và số lượng của việc đào tạo nguồn nhân lực, đội ngũ cán bộ, chuyên gia về biển đảo, đặc biệt là các chuyên gia pháp lý tham gia đàm phán, ký kết và thực thi các thỏa thuận hợp tác cùng phát triển. Bất kể sự yếu kém nào về phẩm chất và trình độ của đội ngũ này đều ảnh hưởng nghiêm trọng đến kết quả đàm phán nội dung các thỏa thuận và lợi ích của quốc gia trong quan hệ với các quốc gia khác. Ngoài ra, cũng cần chú trọng tới đội ngũ chuyên gia kỹ thuật; các lực lượng quản lý, thực thi hoạt động hợp tác cùng phát triển trên biển và lực lượng lao động trên biển. Lực lượng lao động trên biển có vai trò quan trọng trong việc hiện diện dân sự và thực hiện các hoạt động hợp tác trên biển. Lực lượng này cần được nâng cao chuyên môn, kỹ năng nghề nghiệp và trang bị kiến thức pháp luật quốc gia, quốc tế cơ bản để yên tâm bám biển sinh kế, giảm thiểu những rủi ro, thua thiết trong quá trình hợp tác cùng phát triển trên biển.

Đào tạo, bồi dưỡng và nâng cao trình độ khoa học, và đảm bảo sự tham gia đa ngành của đội ngũ chuyên gia, đặc biệt là các chuyên gia pháp lý trong hoạt động đàm phán, ký kết và thực thi thỏa thuận hợp tác cùng phát triển. Đội ngũ chuyên gia chính là nhân tố quyết định sự thành bại của việc thiết lập và thực thi thỏa thuận khai thác chung, do đó, bất kỳ sự yếu kém nào về phẩm chất, trình độ của đội ngũ này cũng đều ảnh hưởng nghiêm trọng tới hiệu quả và khả năng thực thi các giải pháp khai thác chung này. Chính vì thế, Việt Nam cần chú trọng tới nhân tố nguồn nhân lực, và coi đây như điều kiện đảm bảo then chốt tạo nên những thành công đột phá trong quá trình hợp tác khai thác chung.

Ba là, xây dựng cơ chế hợp tác trong nước quốc tế, phối hợp phục vụ các hoạt động đàm phán, ký kết và thực thi thỏa thuận khai thác chung. Một cơ chế hợp tác hiệu quả trong phạm vi quốc gia sẽ tạo điều kiện thuận lợi cho việc thiết lập và thực thi thành công các thỏa thuận khai thác chung bởi lẽ hoạt động khai thác chung trên biển liên quan đến nhiều lĩnh vực quản lý Nhà nước khác nhau (tài nguyên, môi trường biển, nghiên cứu khoa học, an ninh quốc phòng, giao thông vận tải, du lịch, pháp lý, ngoại giao, quản lý hành chính...) và do đó đòi hỏi sự phối hợp hoạt động của rất nhiều cơ quan, bộ phận. Bên cạnh đó, để triển khai thành công các chương trình hợp tác cùng phát triển, cần có sự kết hợp nhuần nhuyễn giữa các quốc gia nhằm giúp mỗi bên nắm bắt tình hình kịp thời và nhanh chóng xử lý khi có các sự cố xảy ra.

Bốn là, xây dựng cơ sở vật chất kỹ thuật, tài chính: Mô hình hợp tác cùng phát triển có được xây dựng và thực thi hiệu quả hay không còn phụ thuộc vào yếu tố cơ sở vật chất, hạ tầng và khoa học công nghệ. Mặc dù cơ sở vật chất hạ tầng, khoa học kỹ thuật và công nghệ biển Việt Nam đã đạt được những kết quả bước đầu nhưng nhìn chung quy mô còn nhỏ bé và đang ở trình độ thấp hơn nhiều so với các nước trên 
thế giới và khu vực. Trong thời gian tới, chúng ta phải xây dựng hệ thống cảng biển, giao thông biển, thông tin liên lạc trên biển phải đủ hiện đại để tạo điều kiện cho các tàu thuyền dễ dàng tiến hành các hoạt động thăm dò, khai thác, nghiên cứu, quản lý, bảo vệ trong khu vực hợp tác. Các tàu thuyền đánh cá cần có công suất lớn, được trang bị hiện đại, đủ khả năng hoạt động xa bờ. Hệ thống cảng biển, giao thông biển cũng cần sớm khắc phục tình trạng lạc hậu nhằm tạo điều kiện thuận lợi cho hoạt động hợp tác cùng phát triển với các nước khác. Đối với các hoạt động hợp tác nghề cá và dầu khí, chúng ta cần nghiên cứu các kỹ thuật khai thác, các phương tiện kỹ thuật thăm dò, đánh bắt hiện đại vừa đảm bảo năng suất vừa bảo tồn các tài nguyên biển, không gây ô nhiễm môi trường biển.

Phát triển nguồn lực tài chính cũng là một trong những điều kiện đảm bảo then chốt cho việc thiết lập và thực thi mô hình hợp tác cùng phát triển giữa Việt Nam và các nước. Hiện nay, chúng ta cần đầu tư hơn nữa vào công tác nghiên cứu các vấn đề trên Biển Đông, đầu tư vào khoa học kỹ thuật và xây dựng cơ sở hạ tầng nhằm phục vụ cho việc xây dựng và thực thi mô hình hợp tác cùng phát triển trên Biển Đông bằng cách thu hút đầu tư trong nước, nước ngoài, tranh thủ sự hỗ trợ của các tổ chức quốc tế...

\section{Kết luận}

Hợp tác cùng phát triển, trên thực tế, là một giải pháp phù hợp với pháp luật và thực tiễn quốc tế, có thể áp dụng cho việc dàn xếp tranh chấp tạm thời tại một số khu vực ở Biển Đông hiện nay. Tuy nhiên, để thực hiện giải pháp này tại Biển Đông, điều đầu tiên Việt Nam chắc chắn phải đề cập tới là vấn đề chủ quyền của Việt Nam trên Biển Đông. Việt Nam sẽ chỉ tiến hành hợp tác cùng phát triển trên cơ sở Trung Quốc và các quốc gia khác tôn trọng chủ quyền của Việt Nam đối với Hoàng Sa và Trường $\mathrm{Sa}$ cũng như chủ quyền, quyền chủ quyền và quyền tài phán đói với các vùng biển, thềm lục địa theo quy định của luật pháp quốc tế. Vì vậy, việc hợp tác này nếu được hiện thực hóa trong tương lai chắc chắn sẽ đem lại nhiều thuận lợi cũng như thách thức cho Việt Nam. Do vậy, cần có những nghiên cứu, xem xét, cân nhắc kỹ lưỡng trong việc chuẩn bị, ký kết và tiến hành hợp tác cùng phát triển với các nước trên Biển Đông, bảo vệ chủ quyền và quyền tài phán quốc gia, góp phần duy trì ổn định, hòa bình trong khu vực và trên thế giới.

\section{Lời cảm ơn}

Bài viết này được thực hiện trong khuôn khổ Đề tài cấp Đại học Quốc gia Hà Nội, mã số QG.16.64, "Những nội dung trái pháp luật quốc tế trong chính sách, pháp luật biển của Trung Quốc trên Biển Đông', từ năm 2016 đến năm 2017, do GS.TS. GVCC Nguyễn Bá Diến chủ nhiệm.

\section{Tài liệu tham khảo}

[1] Xem thêm PGS.TS. Nguyễn Bá Diến (2013), Hợp tác cùng phát triển ở các vùng biển trong pháp luật và thực tiễn quốc tế, Nxb. Thông tin và Truyền thông.

[2] Tác giả: Dương Danh Huy - Quỹ nghiên cứu Biển Đông, "Gác tranh chấp, cùng khai thác" kiểu Trung Quốc, Cập nhật: 21/01/2010 07:00 GMT+7.

[3] Bộ Ngoại giao Trung Quốc. Set aside dispute and pursue joint development. 17/11/2000. Trên mạng: http://www.fmprc.gov.cn/eng/ziliao/3602/3604/ t18023.htm]

[4] 余民才（Yu Min Cai, “Các vấn đề pháp lý của việc thăm dò và khai thác dầu khí trên biển", NXB Đại học Nhân dân Trung Quốc, xuất bản năm 2001.

[5] Nhật báo Nhân dân Trung Quốc, ngày 14/12/1990.

[6] Nhật báo Nhân dân Trung Quốc, ngày 8/6/1991.

[7] Nhật báo Nhân dân Trung Quốc, ngày 23/7/1992.

[8] Văn Hội Báo, ngày 23/8/1997, theo Tài liệu tin tức điện tín quốc tế bản $\mathrm{A} 4$. 
[9] Tuyên bố hợp tác CHND Trung Hoa và lãnh đạo các nước ASEAN - Hợp tác Trung Quốc và ASEAN hướng tới thế kỉ 21. Báo Giải phóng quân Trung Quốc, ngày 17/12/1997.

[10] T. Lam. Hội thảo quốc tế về Biển Đông. Vietnamnet, $25 / 11 / 2009$ http://www.vietnamnet.vn/chinhtri/200911/Hoi -thao-quoc-te-ve-Bien-Dong-880652/

[11] Huỳnh Phan, Giải quyết tranh chấp Biển Đông trong mắt học giả Trung Quốc, Vietnmanet,
07/12/2009.

http://tuanvietnam.vietnamnet.vn/2009-12-04giai-quyet-tranh-chap-bien-dong-trong-mathoc-gia-trung-quoc

[12] Xuân Linh, Chờ điều kiện chín muồi giải quyết tranh chấp Biển Đông. Vietnamnet, 6/1/2010, http://vietnamnet.vn/chinhtri/201001/Cho-dieukien-chin-muoi-giai-quyet-tranh-chap-bienDong-888092/

\title{
The Chinese Policy of "Setting aside Disputes and Pursuing Joint Development" in the East Sea and Solutions for Vietnam
}

\author{
Nguyen Ba Dien, Nguyen Hung Cuong \\ VNU School of Law, 144 Xuan Thuy, Cau Giay, Hanoi, Vietnam
}

\begin{abstract}
Joint development (joint exploitation) is in reality the need and the suitable solution, which could nowadays be applied in settlement of disputes within some areas in the East Sea. However, Vietnam has to be extremely cautious and recognize China's ambition behind the policy of "setting aside disputes and pursuing joint development". This article first presents an overview of the named policy of China from its formation to its basic contents and then puts forward some solutions for Vietnam in implementing the joint exploitation in the East Sea while maintaining the sovereignty of the parties of dispute. Vietnam will only implement joint exploitation provided that China respects Vietnam's sovereignty over the Hoang Sa (Paracel Islands) and Truong Sa (Spratly Islands) as well as its sovereign rights and jurisdiction over the exclusive economic zone and continental shelf adhered to the United Nations Convention on the Law of the Sea 1982.
\end{abstract}

Keywords: Policy, setting aside disputes, pursuing joint development, China, the East Sea, solution, Vietnam. 